\title{
Energy Transition in Rural Areas - Supporting Local Energy Planning by the Development of an Online-Tool for Identification and Promotion of Energy-Efficiency and the Use of Renewables.
}

\author{
Uwe Caemmerer-Seibel ${ }^{1}$, Andrea Lück ${ }^{1}$, Ammar Osman $^{1}$, Gerd Kiesel ${ }^{1}$, Conrad Völker ${ }^{1}$, \\ Hans Wilhelm Alfen ${ }^{2}$, Daniel Cebulla ${ }^{3}$ \\ ${ }^{1}$ BAUHAUS-University Weimar, Department Building Physics, Germany \\ ${ }^{2}$ BAUHAUS-University Weimar, Department Construction Economics, Germany \\ ${ }^{3}$ JENA-GEOS-Engineers, Jena, Germany
}

\begin{abstract}
Energy transition as a process aims to mitigate the effects of climate change at urban scales. It faces obstacles such as multiple stakeholders, complex technical and political decision-making, and unclear funding structures. The potential use of renewable energy, as well as embedding energy strategies in local economic development and in the role of municipalities is highly considered. Energy planning demands high resources, which are limited especially in rural areas. They are not appropriately focused by current energy planning tools. If any, only a few lighthouse-projects like energy cooperatives exist, mostly driven by private initiatives. The resulting online tool provides rural communities a decision support tool for energy transition which enables them to overcome the obstacles with few resources.
\end{abstract}

\section{Introduction}

Climate change and the escalating energy prices have created a reorientation to the focus of projects in energy planning (Ascione et al., 2013). A mitigation approach in the adaptation of more efficient energy consumption strategies and to an environmentally responsible energy sources as an alternative to fossil fuels is envisaged (Iwaro and Mwasha, 2010). With the merge of the high energy targets of the European Union (EU) for the upcoming period from 2020-2030 the necessity of energy planning at larger scale is of paramount importance (European Commission, 2014).

Energy planning at the urban scale is a complex process especially with multiple stakeholder and a number of obstacles to overcome (Cajot et al., 2017). The process of energy transition is considered the key solution to tackle the change in energy systems, considering that energy transition demands deeper interaction of municipalities in the process (Sperling et al., 2011). Transition management is as important as the process itself (Vandenbroeck, 2012). Francis and Pye (2018) enhance the importance of better integration of the stakeholders to define and design a more flexible policy for the transition. Yet with the different approaches to energy planning, challenges appear in "overlapping scientific, political and administrative complexities". These challenges affect the model's quality and the quality of data collected in turn it is influenced by the different physical and administrative scales (Cajot et al., 2017).
The development of urban energy maps sets a ground for analysis of energy performance where energy planning is equally initiated for existing buildings and updated for new ones. Energy performance databases of the urban context usually rely on data collected using Geographical Information Systems (GIS), visualised and developed to provide the needed information for the preparation of energy planning (Ascione et al., 2013).

For rural areas, however, this procedure so far has not been implemented, as they often need high quality energy-data and high investments in expertise at an early stage of planning process. In particular, free-access online-tools with immediate available results and recommendations in early strategic planning phases do not exist at all (Benedek et al., 2018).

Currently, there is a number of online tools that serve comparable aims of energy transition, such as ECOSPEED (ECOSPEED AG, 2018) and HOTMAPS (HOTMAPS, 2018). These tools vary in their supplied service, though both tools lack of the calculation and sizing of renewable energy based on the information of the specific location.

The approach of the authors based on the abovementioned challenges of future energy planning and transition in rural areas would result in project (TRAIL 2017-2019). The project consists of partners from science and practice, combing theoretical and practical expertise to develop and implement a decision-support-tool for local users and decision makers at the municipality level. Aiming to support small communities, with less than 10,000 inhabitants, by evaluating complex energy strategies, and assessing potential projects and ensuring social acceptance. This support shall exploit the potential of linking renewable energy with rural development.

Four typical rural municipalities in the German federal state of Thuringia participate in the project to express their requirements and give continuous evaluation of the TRAIL online-tool. These are Kahla with approx. 6,900, Werther with 3,200, Grossobringen with 900 and Neumark with only 500 inhabitants.

\section{Literature Review}

\section{Status quo of Energy planning in rural areas in European Union (EU) and Germany}

Energy regulations and planning in the EU merely depend on the local standards of the member states, as there are no common unified standards, but some broad guidelines 
and targets. However, the plans and aims of the EU concerning energy targets encourage the integration of end users and planners in the process of energy planning in order to achieve the aimed policy: "Energy Performance in Building Directive", which is also eligible for rural areas (European parliament, 2010).

Many of the energy transition discussions are related to urban areas and are connected to Smart City initiatives. Slowly, the focus on rural areas is rising as traceable by discussion around "smart villages" (Poggi et al., 2018). This is not surprising, as around $58 \%$ of the population live in rural areas in Germany (Federal Ministry of Food and Agriculture (2013). Additionally, 10\% of land use is assigned for the energy system in Germany, almost all of which is in rural areas. These rural areas provide the space for biomass, photovoltaic or wind power (Gailing and Moss (2016)).

OECD (2012) emphasizes the potentials of linking renewable energy with rural development. Therefore, key factors should be considered like: embedding energy strategies in the local economic development strategy, avoiding to impose unsuitable types of renewable energy on areas that are not suited to them, creating an integrated energy system, assessing potential projects using investment criteria and ensuring local social acceptance by addressing clear benefits to local communities and their engagement in the process.

This potential has actually not been exhausted, if any, only for a few lighthouse-projects like energy cooperatives exist, that are mostly driven by private initiatives (Pfenning (2018), Becker and Naumann (2016)). Furthermore, the installation of renewable energy is highly incentive-driven, which led to rent-seeking behaviours and a competition for the use of land with agriculture and tourism. As a result, many rural communities are even opposing further deployments (OECD, 2012).

\section{Challenges of energy planning and transition}

Comparing urban areas and single buildings would lead to an understanding of the challenges in the process of energy planning (Cajot et al., 2017). The scale of single buildings is defined in terms of area, size, life span, etc. From an energy point of view, it has limited stakeholders, as well as energy and electricity demand (Peter et al., 2009; Strasser, 2015; Zanon and Verones, 2013).

At the urban scale, the complexity occurs by "multiple actors, different scales, long-term implications and uncertainty in the process, methods and basic definitions" (Cajot et al., 2017). Many studies have handled the issue of energy planning and energy efficiency at the urban scale, and (Zanon and Verones, 2013) argue that energy efficiency "must be addressed by connecting the building scale with the urban one".

The responsibility of energy planning has expanded from a limited group of specialists including authorities on various levels to concerned companies and operators to further parties. This expansion is caused by the transition of the approach to energy planning from passive demand supplied from urban sources to active organisation of energy within every geographical boundary (Coelho et al., 2010).

The leading role of municipalities is considered pivotal for the energy transition and energy planning (Sperling et al., 2011). At the municipality level, the problems appear in the multiple and sometimes conflicting problem statements because of the background of every stakeholder of the project. The various angles of view of the stakeholders to the problem creates different solution tactics, notwithstanding the complexity and uncertainty as well as the instability of the problem from scientific, political and administrative perspectives (Cajot et al., 2017).

Here, the definition of energy planning in this research focuses on the "strategic" energy planning as described by (Sperling et al., 2011) where a systematic integration appears between the various levels of stakeholders.

Challenges at the energy transition level constitute in high technical complexity (Kirnats et al., 2018), politically complex decision-making and unclear funding programme structures. Planning demands high expert knowledge and requires considerable resources in terms of cost, time and staff.

\section{GIS-based energy planning and tools}

Geographical Information Systems (GIS) has been experienced as a tool for urban energy planning in various researches ((Byrne et al., 2008), (Ascione et al., 2013), (Bugs et al., 2010)), mainly as tool for energy audits of buildings. It allows to collect information on urban scale and arrange information in various layers for energy analysis, research and planning (Ascione et al., 2013). GIS embeds geo-referencing process as a methodology (Favretto, 2000) as referencing based on a system of coordinates within the known studied domain.

All available GIS-based solutions like ECOSPEED toolbox and HOTMAPS have other approaches and deliverables and are much cost and staff intensive and focus mainly on urban areas. A recent evaluation of 900 German energy projects by (Kirnats et al., 2018) revealed that in most cases the research projects are lacking a connection to their future applicants. Additionally, there are no digital planning tools at urban quarter or broader scale. Hence, systematic approaches for holistic modelling of overall system incorporating actively users and integrated energy systems are missing (Kirnats et al., 2018).

The use of Software development and SCRUM (see www.scrum.org), that are substantial components of organisation's programme, reduces unpredictability and solves complex problems as (Wheeler, 2011) defines it as "significant component of almost every organisations programme". This problem solving methodology applies empiricism as SCRUM presents heuristic as an alternative to algorithmic approach. (Schmidt, 2013) explains the importance of software development as it appears in the success of the project as it organises the technicality and objectives of the project, as well as organises and controls the inputs from stakeholders and the product of the software. 


\section{Methodology}

Based on the literature review the TRAIL project chooses an iterative approach as follows: The methodology of the project is based on an iterative loop of five steps. Starting by the assessment of framework conditions and requirements, derivation of software requirement specifications and the specification of functional targets, determination of software development, then test the results, adaptation, and eventually returning back to feed in the municipalities for further evaluation (see Figure 1).

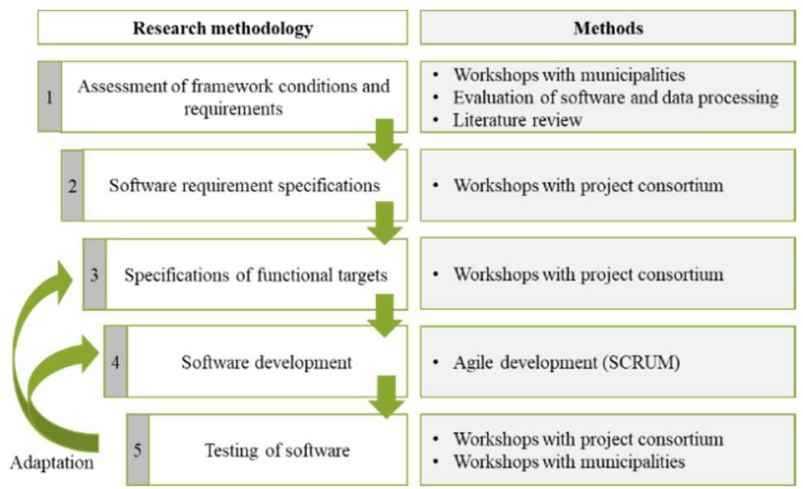

Figure 1: TRAIL methodology.

\section{Results}

\section{Step 1: Framework conditions and requirements}

Initially, the results of the first step show that the size and administrative status of the four municipal case studies are different yet they present little to no work for measures of energy transition. These municipalities are different in their governances as they are either independent or part of an association of administrations. Results of TRAIL workshops with municipalities showed, that they offer little preparatory data and suffer from limited financial and human resources for energy transition. Hence, they wish for a TRAIL software designed to their local requirements.

This set of scarcities resulted in little resources and administrative support, different IT-infrastructures and eventually no time or resources for data collection of energy transition. Table 1 summarizes the results of step 1 , below.

Table 1: Results of step 1 .

\begin{tabular}{|c|c|c|}
\hline \multicolumn{3}{|c|}{ Assessment of framework conditions and requirements } \\
\hline & Municipalities in rural areas & Energy transition \\
\hline 丞泀 & $\begin{array}{l}\text { - Little financial resources } \\
\text { - Hardly any staff and/or expertise } \\
\text { - Little motivation and support } \\
\text { - Few lighthouse projects } \\
\text { - Hardly any administrative support } \\
\text { - Different IT infrastructures }\end{array}$ & $\begin{array}{l}\text { - Technical high } \\
\text { complexity } \\
\text { - Politically difficult } \\
\text { - Unclear funding } \\
\text { structures }\end{array}$ \\
\hline 莺 & $\begin{array}{l}\text { Data collection with few } \\
\text { participation } \\
\text { - Stakeholder participation } \\
\text { - Possibility of citizens' information } \\
\text { and involvement } \\
\text { - Addressing private households, } \\
\text { industry, trade and service sector }\end{array}$ & $\begin{array}{l}\text { - High expert } \\
\text { knowledge required } \\
\text { - High resources } \\
\text { demand (costs, time, } \\
\text { staff) } \\
\text { - Political will / } \\
\text { cooperation necessary }\end{array}$ \\
\hline
\end{tabular}

\section{Step 2: Software requirement specifications}

As a result of the assessment, the Software Requirement Specifications (SRS) were derived. Along several workshops of the TRAIL consortium, aims, functions and necessary data, an in-depth description of the TRAIL-tool has evolved. The most important results are summarised in Table 2, below.

Table 2: Result of step 2 - Overview SRS

\begin{tabular}{|l|l|}
\hline - Decision-support-tool for rural municipalities in energy transition \\
\hline - Low-cost, easy-to-use Online-platform \\
\hline - Runs with internet-connection and browser \\
\hline - Well-designed, user-friendly interfaces \\
- No expert knowledge needed \\
- Scalable, modular, expandable
\end{tabular}

\section{Step 3: Specifications of functional targets}

The functional targets based on the above-mentioned SRS were derived in step 3. They describe capabilities and appearance of the software as well as interactions with the users. They set the guideline for the developers and are a continuing reference point during the iterative programming process. Table 3 , below, shows an overview of the specified functional targets. Here, most research had to be done with versioning, data collection and processing as well as defining measures, evaluation criteria and calculation algorithms, which is described further below.

Table 3: Result of step 3 - Functional targets

\begin{tabular}{|c|c|}
\hline 3 & Functional targets \\
\hline$\frac{\frac{3}{2}}{\frac{2}{2}}$ & $\begin{array}{l}\text { - "Typo3": free enterprise-class CMS based on PHP } \\
\text { - Three versions: TRAILstarter-TRAILplus-TRAILpro } \\
\text { - Information: Newsfeed, newsletter and guided tutorials } \\
\text { - } 10 \text { Modules with different viewing depth } \\
\text { - Main output: "Action"-sheets } \\
\text { - ... }\end{array}$ \\
\hline & $\begin{array}{l}\text { - Maps for actual heat and power demand on urban scale } \\
\text { - Maps for potential of renewable energy (PV, geothermal, biomass) } \\
\text { - } \text { Modularization of measures, individually for each municipality } \\
\text { - } \text {-step data-processing (selection-info-input-calculation-output) } \\
\text { - Funding database } \\
\text { - } \ldots\end{array}$ \\
\hline$\overline{\tilde{J}}$ & $\begin{array}{l}\text { - } 100 \times 100 \text { grid: heat and power demand } \\
\text { - Based on official geo- and census-Data } \\
\text { - Classification of } 5 \text { building types based on Tabula-typology } \\
\text { - Software used for classification: "R" } \\
\text { - PV - interface to existing online-database } \\
\text { - Geothermal and biomass-potential algorithms } \\
\text { - } \quad \ldots\end{array}$ \\
\hline
\end{tabular}




\section{Versioning}

The TRAIL-tool is developed in three versions (starter, plus and pro). This approach was chosen for responding to different aspiration levels by the municipalities and offering quickly a first overview of the energetic state of the municipality, which can be tested and improved iteratively at later stages. The details of the versions are the following:

\section{Data processing approach for TRAILstarter}

A bottom-up approach was developed including data processing of freely accessible coefficients for heat and power demands, and statistical and spatial data. Based on these data, sums of energy demand, demand per living area and inhabitant could be calculated. The municipalities were divided into $100 \times 100 \mathrm{~m}$ grid cells as a minimum limit because of privacy and data protection reasons (Bundesamt für Kartographie und Geodäsie (2017)). Statistical data of municipalities and publicly available data (GIS, Census) are allocated to the grid cells. Based on this allocation, the distribution of energy and power demand can be assessed and visualized.

All of the data processing algorithms are written within the programming language $\mathrm{R}$ (Team (2017)). The following packages where used to get functions for geodata processing: sf (Pebesma (2018b)), rgdal (Pebesma (2018b)), lwgeom (Pebesma (2018a)) spdep (Bivand et al. (2013)) and raster (Hijmans (2017)).

The data processing approach is implemented in TRAILstarter and its sub-steps are introduced subsequently. The advantages of the chosen approach are: No data collection needed by municipality and immediate availability of results.

\section{Classification of residential building types}

The TRAIL online-tool has a database of the buildings and their typology linked to their geolocation. For residential buildings, this is important since determination of energy demand is based on the knowledge about their correct types. There exist different categories and each type has its specific demand per square meter of living space. The demand is influenced by different factors such as building size, number of floors, existing period and number of neighbouring buildings.

Based on classification of Tabula project, five different types of residential buildings where chosen because they are the most relevant for rural areas: detached/ semidetached single-family house, row housing, multifamily house, great multi-family house and high-rise building (Typology Approach for Building Stock Energy Assessment (2012)).

In the next step, each residential building must be assigned to the chosen five categories based on open source data only. Processed data packages are freely provided by Thuringian land surveying office including building outlines, land parcels, address coordinates and 3D buildings in level of detail 2 (LOD2) (Open Geospatial Consortium (2012)).

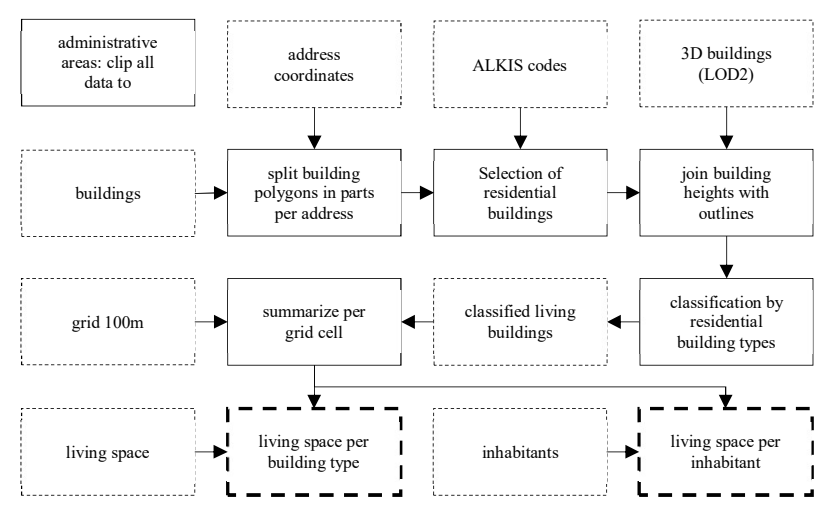

Figure 2: Classification algorithm of building types.

The classification algorithm is illustrated in Figure 2. In case of block apartment buildings that consist of various entrances, the energy demand estimation considers each entrance as a separate house. So, in the first step, building outlines need to be split using corresponding address coordinates of the entrances in their sub-parts within the unified outline of the building (Figure 3 ).

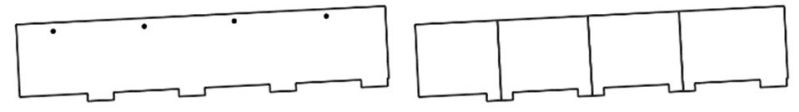

Figure 3: Splitting of building outlines per address coordinates.

Necessary information for the classification of building types are spread over different data sets such as ground use (land parcels), building function and building height (3D buildings). All data were combined, and the building function was used to specify residential buildings. Residential buildings were classified according to the five building types by setting specific thresholds for gross floor area and building height (Figure 4). With the knowledge of the building types per grid cell, the living space per type and per inhabitant can be calculated.

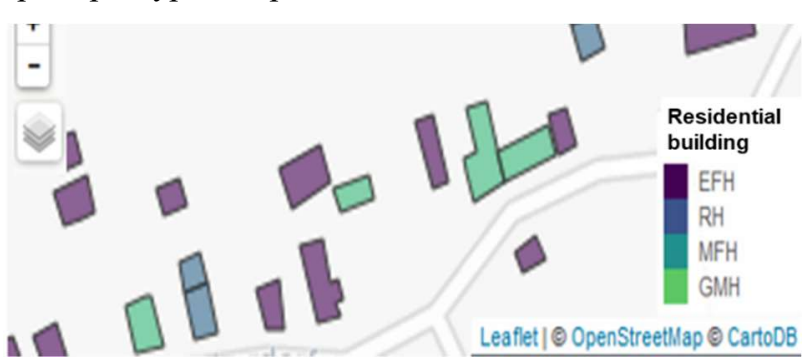

Figure 4: Example of building type classification.

For further calculations of heat and power demand, the following data were used: Census of the year 2011 per grid cell (Federal Statistical Office (2011), number of inhabitants, number of buildings in different age of building classes, number of households in different subcategories, coefficients for heat demands by age of building class (Typology Approach for Building Stock Energy Assessment, 2012) and coefficients for power demands by household subcategory (Federal Statistical Office of Germany (Statistisches Bundesamt (2019)). 


\section{Calculation of heat demand}

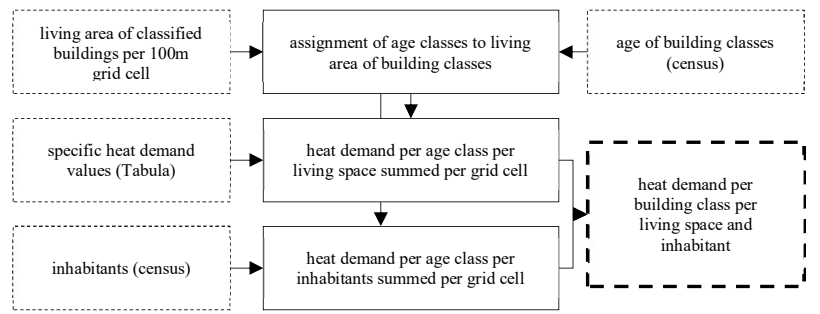

Figure 5: Calculation of heat demand.

For determining heat demand, the number of buildings in different ages of building classes from census data were combined with the age of building classes by Tabula (Typology Approach for Building Stock Energy Assessment (2012)). Based on that, the following formula was used to calculate the total heat demand $D_{\text {heat total }}$ per cell

$$
D_{\text {heat total }}=A_{\text {living }} \cdot Q_{\text {building age }} \cdot C_{\text {heat }}
$$

Where $A_{\text {living }}$ is the living space per building type, $Q_{\text {building age }}$ is the percentual quotes of buildings per age of a building class and $C_{\text {hea }}$ is the corresponding heat demand coefficient per square meter living space per building type per age of building class.

In addition to the total heat demand per cell, the heat demand per square meter $D_{\text {hea }} \mathrm{m}^{2}$ and inhabitant $D_{\text {hea inhabitan }}$ was calculated by the following formulae

$$
D_{\text {heat } m^{2}}=\frac{D_{\text {heat total }}}{A_{\text {living }}}
$$

and

$$
D_{\text {heat inhabitant }}=\frac{D_{\text {heat total }}}{n_{\text {inhabitants }}}
$$

Where $n_{\text {inhabitants }}$ is the number of inhabitants from census data. The above calculations result in a map with heat demand as in the example in Figure 6 below:

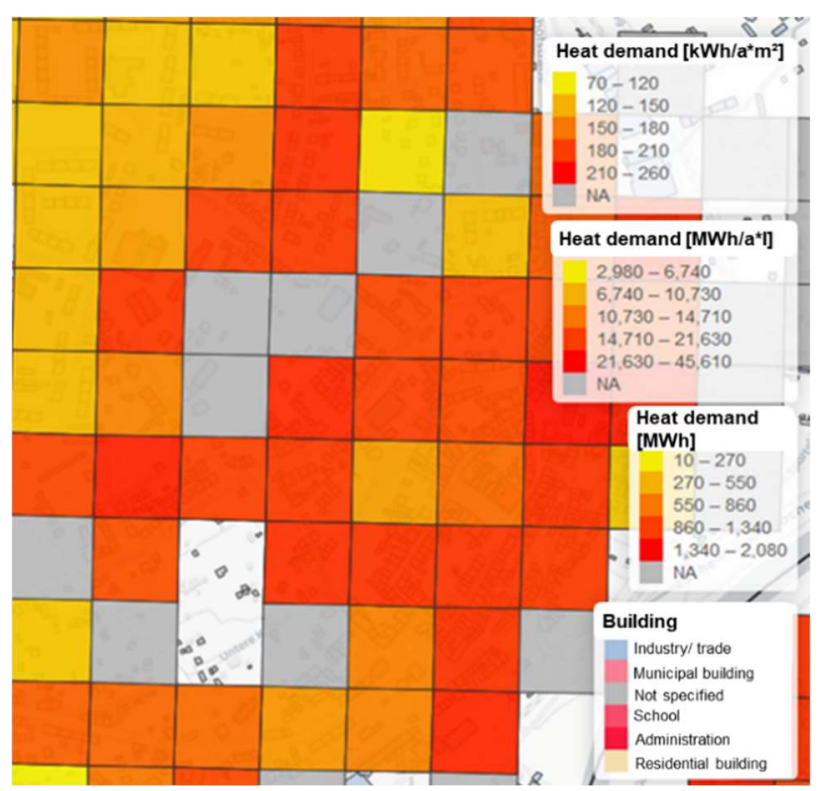

Figure 6: Sample map of heat demand.

\section{Calculation of power demand}

The total power demand $D_{\text {power total }}$ per cell was calculated based on the number of households per the specific cell $n_{\text {households }}$ retrieved from the census data then multiplied by the power demand coefficients $C_{\text {power }}$ :

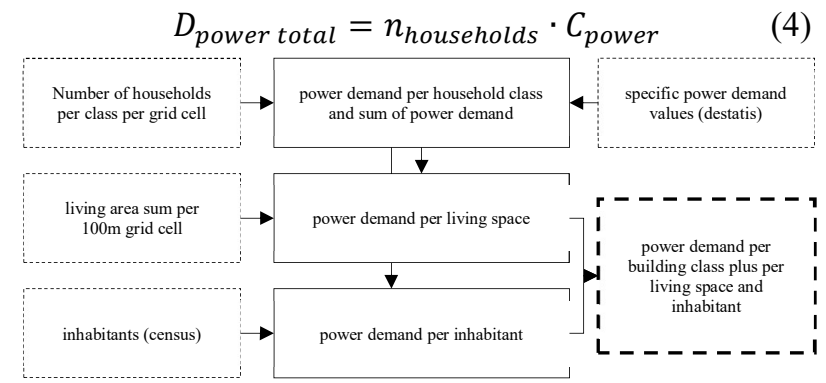

Figure 7: Calculation of power demand.

The number of households was summarized in the following categories: 1 person, 2 people and at least 3 people-household. The power demand per inhabitant was calculated in the same way as the heat demand. The defined heat and power demand and their allocation to the grid cells can be used to project the renewable energy (RE) potential for the municipality.

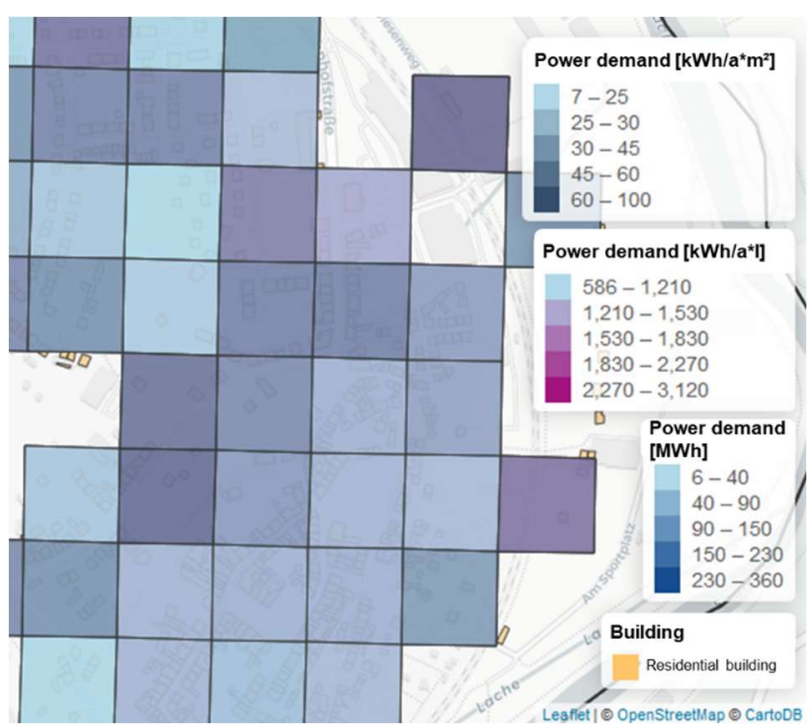

Figure 8: Sample map of power demand.

\section{Renewable energy potentials}

To give specific guidance to the municipalities for their energy planning, Renewable Energy (RE) potentials are defined and provided within the version TRAILplus. The status quo of energy from wind power, hydropower, photovoltaic (PV), sewage gas, landfill gas and biomass (forest and agriculture) are represented by blending geodata from publicly accessible databases with data from transmission system operators for identifying the locations of the individual plants. The results are illustrated on federal level, though only wind power and biogas plants are accessible on municipality level.

TRAIL calculates the RE potential for PV, waste heat, biomass -from forest and agriculture-, and geothermal energy. However, it does not focus on wind and water potentials, since wind priority areas cannot be influenced 
by the municipality and the potential of water is already exhausted in Thuringia. For assigning PV potentials to the municipalities, pre-calculated geodata from public databases are incorporated via an interface. Subsequently, maximum number of installable modules and potential $\mathrm{CO}_{2}$ savings were calculated, outliers were detected and yields per 100x100m grid were spatialized. Finally, yields were set against energy demand from TRAILstarter version. The resulting maps of TRAILplus shows building suitability, roof suitability, amount of irradiance, PV yield in MWh (per roof) and potential PV in MWh (per grid cell) (Figure 9).

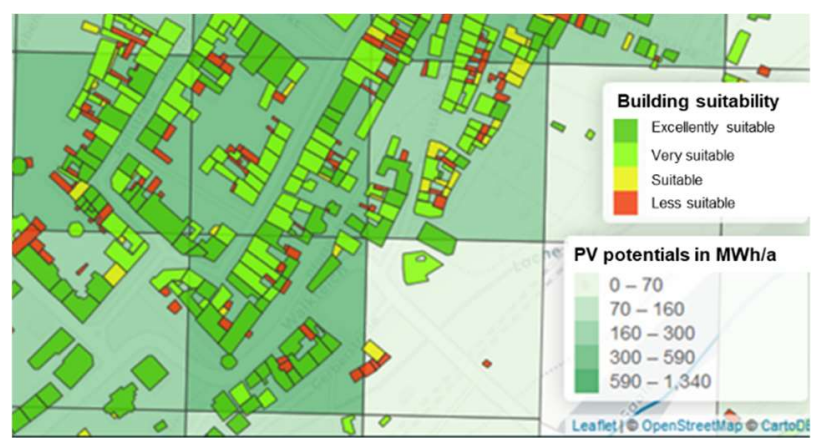

Figure 9: Sample map of PV-potential.

The methodology for identifying geothermal and biomass potentials is almost identical to the one of $\mathrm{PV}$, the resulting maps are shown in Figure 10 and Figure 11. Due to space limitation, their methodologies cannot be presented in detail in this paper.

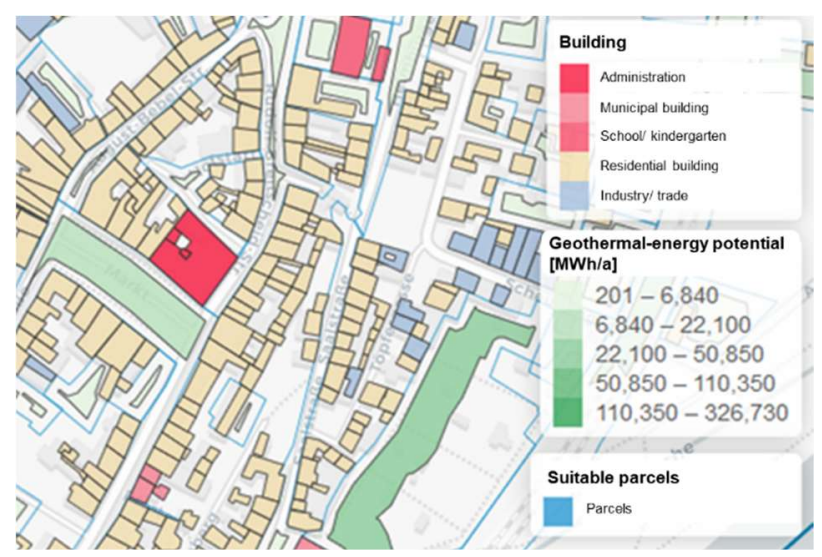

Figure 10: Sample map of geothermal energy-potential.

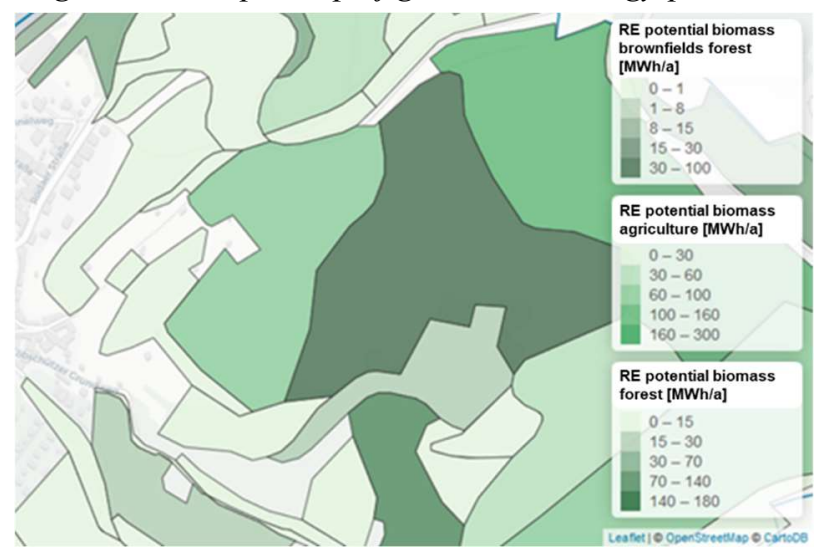

Figure 11: Sample map of biomass-potential.
Analogous to the other modules of TRAILplus, users obtain specific action sheets concerning employment of RE measures in municipalities.

\section{Modularisation}

Since reasonable measures or the desired fields of actions differ for each municipality, possible measures were divided into modules. This facilitates orientation and helps with the systematic creation of individual catalogue of measures. Additionally, municipalities can choose their preferred field(s) of action and focus on certain modules without being obliged to evaluate all other modules. The TRAILplus version comprises the following nine modules:

Table 4: Modules and examples of measures

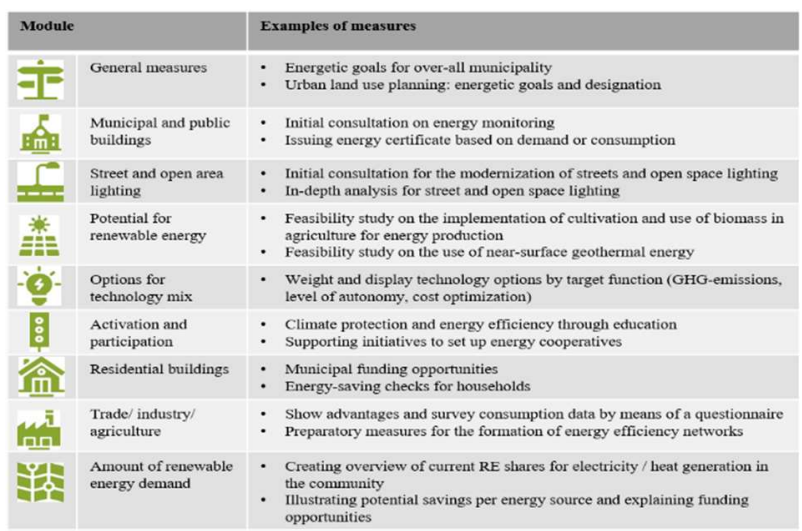

The development of measures focused on the first six modules of Table 4 as the municipalities emphasized as higher priority.

\section{Evaluation criteria and action sheets}

Seven evaluation criteria were developed for assessing the modularly structured measures (see Table 5 below).

Table 5: Evaluation criteria.

\begin{tabular}{|c|c|c|}
\hline \multicolumn{2}{|c|}{ Evaluation Criteria } & \multirow{2}{*}{$\begin{array}{l}\text { Description } \\
\text { - Cost for initiating and/or implementation of measure }\end{array}$} \\
\hline$\hat{\boldsymbol{\epsilon}}$ & (Investment) Costs & \\
\hline & $\begin{array}{l}\text { Savings of energy } \\
\text { costs }\end{array}$ & - Amount of cost which can be saved due to measure \\
\hline & $\begin{array}{l}\text { Savings of } \mathrm{CO}_{2} \\
\text { emissions }\end{array}$ & - Amount of $\mathrm{CO}_{2}$ emissions which can be saved due to measure \\
\hline & $\begin{array}{l}\text { Period up to } \\
\text { occurrence of effects } \\
\text { of the measure }\end{array}$ & - Time frame until effects of measure are appearing \\
\hline (6) & $\begin{array}{l}\text { Municipalities' } \\
\text { organizational effort }\end{array}$ & $\begin{array}{l}\text { - Amount of organizational effort for municipality based on amount of } \\
\text { stakeholders to be involved and amount of actions steps for measure }\end{array}$ \\
\hline 130 & $\begin{array}{l}\text { Impulse effect for } \\
\text { third parties }\end{array}$ & - Amount of target group which is addressed by measure \\
\hline 20 & $\begin{array}{l}\text { Influenceability by } \\
\text { the municipality }\end{array}$ & $\begin{array}{l}\text { - Declariation whether measure is directly or indirectly influenceable } \\
\text { by municipality }\end{array}$ \\
\hline
\end{tabular}

Consequently, the municipalities can develop a specific catalogue of measures based on their preferences for the evaluation criteria. These criteria were derived from literature review and feedback of the municipalities and have different scales (2-5 intervals or characteristics).

The action sheets will be the core deliverables summarizing the contents of the research agenda. Besides the evaluation criteria, the action sheets include the description of the measure, contact persons for next steps, stakeholders to be involved, necessary preconditions and/or obstacles to overcome, next (mini-) steps and possibilities of funding. 


\section{Step 4 and 5: Software development and testing}

The fourth step, software development, started with establishing a hierarchy of implementations of the modules and applying the "SCRUM"-Method: "Sprints" were defined to determine form, content, design and typical use-cases. Based on the use-cases a developer's version was programmed, quality checked and first tested by the TRAIL-partners. From there a version is installed for pilot-users of the municipalities introducing (step 5). Those users will give feedback during workshops, which will be evaluated, and changes shall be applied where necessary. For the actual pilot see: www.trail-energie.de.

\section{Discussion}

The first set of interim results of the TRAIL project showed that the chosen methodology lead to the desired results. The municipalities' feedback revealed that the tool is meeting their requirements. It fits their level of expertise, requiring low resources in terms of cost, time and staff. TRAIL delivers an easy start for energy transition in rural areas, allowing municipalities to evaluate and identify possible measures according to their local preferences. It can therefore simplify the technical complexity and support the decision-making processes.

As a free-access online-tool with immediate available results and recommendations it meets the identified functional targets, including developed algorithms for the calculation of heat and power demand, classification of building types as wells as RE potentials for PV, biomass and geothermal energy. Evaluation of the accuracy of this data is still in progress.

Regarding the limitations of the level of detail by the chosen methodology, it could be argued that the data accuracy analysis will reveal whether TRAIL is appropriate to embed energy planning in the local economic development strategy, assess potential projects and ensure social acceptance by addressing clear benefits to local communities and their engagement in the process.

\section{Conclusion and Future Research}

A systematic approach is addressed by the TRAIL-project and includes measures for interconnected concepts for buildings and urban quarters, active involvement of users and consideration of integrated energy (Kirnats et al. (2018). It incorporates the specific requirements and framework conditions of rural municipalities for supporting them in the decision-making processes of energy transition.

The innovation of TRAIL exists in the fully automated algorithm classifying all residential buildings with their specific heat and power demand and the potential to use $\mathrm{RE}$ in a rural municipality. Furthermore, the tool innovates the support in the decision-making process in local energy-concepts by evaluating these data and proposing suitable and adaptable measures. Measures are recommended based on the evaluation by seven evaluation criteria and user's preferences. In addition, it is easy-to-use, flexible and low-cost. Therefore, it can be used by small administrations to get a much better understanding of energy transition.
Within the development of the current tool several research gaps were identified. Their elimination would enhance the practicability, level of detail and scope of investigations. This includes the consideration of intermunicipal cooperation, extensions of technical solutions for linking several infrastructure sectors, increasing data accuracy with new methods, simplifying data collection and considering aspects of data protection. These aspects are addressed in a subsequent project proposal.

\section{Acknowledgments}

The project is funded by German Ministry of Economic Affairs and Energy $(B M W i)$ under the grant agreement $n^{\circ}$ FKZ 03ET1433C (commTRAIL). The authors gratefully acknowledge this support and carry the full responsibility for the content of this publication.

We also thank all partners of TRAIL consortium for their fruitful contributions to TRAIL tool. Furthermore, we thank the anonymous reviewers, whose valuable comments enhanced the paper.

\section{References}

Ascione, F., Masi, R.F. de, Rossi, F. de, Fistola, R., Sasso, M. and Vanoli, G.P. (2013), "Analysis and diagnosis of the energy performance of buildings and districts: Methodology, validation and development of Urban Energy Maps", Cities, Vol. 35, pp. 270-283.

Becker, S. and Naumann, M. (2016), Energiekonflikte nutzen: Wie die Energiewende vor Ort gelingen kann, Projektverbund „EnerLOG“ (Leibniz-Institut für Raumbezogene Sozialforschung ZukunftsAgentur Brandenburg Europasekretariat Local Governments focenedek, j., Sebestyen, T. and Bartok, B. (2018), "Evaluation of renewable nergy sources in peripheral areas and renewable nergy-based rural development", Vol. 90, pp. 516-535.

Bivand, R., Hauke, J. and Kossowski, T. (2013), "Computing the Jacobian in Gaussian spatial autoregressive models. An illustrated comparison of available methods", Geographical Analysis, Vol. 45 No. 2, pp. 150-179.

Bugs, G., Garnell, C., Fonts, O., Huerta, J. and Painho, M. (2010), "An assessment of Public Participation GIS and Web 2.0 technologies in urban planning practice in Canela, Brazil", Cities, Vol. 27 No. 3, pp. 172181.

Bundesamt für Kartographie und Geodäsie (2017), "Geographische Gitter für Deutschland. GeoGitter", available at: https://www.geodatenzentrum.de /docpdf/geogitter.pdf (accessed 7 January 2019).

Byrne, J., Corgnati, S.P. and Filippi, M. (2008), "Evaluating the potential of small-scale renewable energy options to meet rural livelihoods needs: GISand lifecycle cost-based assessment of Western China's options", Energy Policy, Vol. 35, pp. 43914401.

Cajot, S., Peter, M., Bahu, J.-M., Guignet, F., Koch, A. and Marechal F. (2017), "Obstacles in energy 
planning at the urban scale", Sustainable Cities and Society, Vol. 30 No. 2210-6707, pp. 223-236.

Coelho, D., Antunes, C.H. and Martins, A.G. (2010), "Using SSM for structuring decision support in urban energy planning.", Ukio Technol. Ir Ekon. Vystym., Vol. 16, pp. 641-653.

ECOSPEED AG (2018), "ECOSPEED. Climate Software Solutions", available at: https://www.ecospeed. ch/private/en/ (accessed October 2018).

European Commission (2014), A policy framework for climate and energy in the period from 2020 to 2030 (Communication), Brussels.

European parliament (2010), EPBD Directive: on the energy performance of buildings (recast).

Favretto, A. (2000), "Nuovi strumenti per l'analisti geografica i GIS Bologna".

Federal Ministry of Food and Agriculture (2013), "Interaktive Deutschlandkarten", available at: https://www.bmel.de/DE/LaendlicheRaeume/Infografiken/_node.html (accessed 11 December 2018).

Federal Statistical Office (2011), "ZENSUS 2011", available at: https://www.zensus2011.de/EN/Home/ home_node.html (accessed 7 January 2019).

Francis, G.N. and Pye, S. (2018), "Uncertainty, politics, and technology: Expert perceptions on energy transitions in the United Kingdom”, Energy Research \& Social Sciences, Vol. 37, pp. 122-132.

Gailing, L. and Moss, T. (2016), Conceptualizing Germany's energy transition: Institutions, materiality, power, space, Palgrave Pivot, [1st ed.].

Hijmans, R.J. (2017), raster: Geographic Data Analysis and Modeling, available at: https://CRAN.Rproject.org/package=raster.

HOTMAPS (2018), "HOTMAPS Project”, available at: http://www.hotmaps-project.eu/hotmaps-project/ (accessed October 2018).

Iwaro, J. and Mwasha, A. (2010), "A review of building energy regualtion and policy for energy conservation in developing countries", Energy Policy, Vol. 38, pp. 7744-7755.

Kirnats, L., Joost, J.-N., Berg, S., Frisch, J. and van Treeck, C. (2018), "Status Quo bei digitalen Werkzeugen und softwarebasierten Lösungsansätzen", Bauphysik, Vol. 40 No. 6, pp. 441-448.

OECD (2012), Linking renewable energy to rural development, OECD green growth studies, OECD publ, Paris.

Open Geospatial Consortium (2012), “OGC City Geography Markup Language (CityGML) En-coding Standard", available at: https://portal.opengeospatial. org/ (accessed 7 January 2019).
Pebesma, E. (2018a), lwgeom: Bindings to Selected 'liblwgeom' Functions for Simple Features, available at: https://CRAN.R-project.org/package=lwgeom.

Pebesma, E. (2018b), sf: Simple Features for $R$, available at: https:/CRAN.R-project.org/package $=$ sf.

Peter, M., Avci, N., Girard, S. and Keim, C. (Eds.) (2009), Energy demand in city regions-methods dynamics of spatial energy consumption., Stockholm, Sweden.

Pfenning, U. (2018), "Eine soziologische Systemanalyse und sozio-ökonomisches Review der Soziotechnik Energiewende", Zeitschrift für Energiewirtschaft, Vol. 42 No. 2, pp. 151-166.

Poggi, F., Frimino, A. and Amado, M. (2018), "Planning renewable energy in rural areas: Impacts on occupation and land use", Energy and Buildings, Vol. 155, pp. 630-640.

Schmidt, R.F. (2013), Software Engineering: Chapter 4 Understanding the Software Project Environment.

Sperling, K., Hvelplund, F. and Mathiesen, B.V. (2011), "Centralisation and decentralisation in strategic municipal energy planning in Denmark", Energy Policy, Vol. 39, pp. 1338-1351.

Statistisches Bundesamt (2019), "Startseite - Statistisches Bundesamt. Destatis", available at: https://www. destatis.de/DE/Startseite.html (accessed 7 January 2019).

Strasser, H. (Ed.) (2015), Implementation of energy strategies in communities--From pilot project in Salzburg, Austria, to urban strategy.

Team, R.C. (2017), "R. A Language and Environment for Statistical Computing", available at: https://www.Rproject.org/.

Typology Approach for Building Stock Energy Assessment (2012), Typology Approaches for Nonresidential Buildings in Five European Countries Existing Information, Concepts, and outlooks: Tabula Thematic Report No. 3.

Vandenbroeck, P. (2012), Working with wicked problems, King Baudouin Foundation, Brussels.

Wheeler, E. (2011), Security risk managemnet: Chapter 13 - A Blueprint for Security.

Zanon, B. and Verones, S. (2013), "Climate change, urban energy and planning practices: Italian experiences of innovation in land management tools.", Land Use Policy, Vol. 32, pp. 343-355. 